\title{
Anti-Inflammatory Activity of Boswellia serrata Extracts: An In Vitro Study on Porcine Aortic Endothelial Cells
}

\author{
Martina Bertocchi (D), Gloria Isani (D), Federica Medici, Giulia Andreani (D), \\ Irvin Tubon Usca $₫$, Paola Roncada, Monica Forni $(\mathbb{D}$, and Chiara Bernardini \\ Department of Veterinary Medical Sciences-DIMEVET, University of Bologna, Ozzano Emilia, Bologna 40064, Italy \\ Correspondence should be addressed to Gloria Isani; gloria.isani@unibo.it
}

Received 21 February 2018; Accepted 11 April 2018; Published 25 June 2018

Academic Editor: Raluca M. Pop

Copyright ( 2018 Martina Bertocchi et al. This is an open access article distributed under the Creative Commons Attribution License, which permits unrestricted use, distribution, and reproduction in any medium, provided the original work is properly cited.

\begin{abstract}
This study is aimed at investigating the cytotoxicity, anti-inflammatory, and angiogenic activities of two Boswellia serrata extracts on primary culture of porcine aortic endothelial cells (pAECs). Chemical characterization of a dry extract (extract A) and a hydroenzymatic extract (extract $G$ ) of $B$. serrata was performed by HPLC using pure boswellic acids (BAs) as standard. In cultured pAECs, extract G improved cell viability, following LPS challenge, in a dose-dependent manner and did not show any toxic effect. On the other hand, extract A was toxic at higher doses and restored pAEC viability after LPS challenge only at lower doses. Pure BAs, used at the same concentrations as those determined in the phytoextracts, did not contrast LPS-induced cytotoxicity. Extract A showed proangiogenic properties at the lowest dose, and the same result was observed using pure AKBA at the corresponding concentration, whereas extract $\mathrm{G}$ did not show any effect on the migration capacity of endothelial cells. In conclusion, an anti-inflammatory activity of B. serrata extracts on endothelial cells was reported, though cytotoxicity or proliferative stimulation can occur instead of a protective effect, depending on the dose and the formulation.
\end{abstract}

\section{Introduction}

The endothelium, uniquely positioned at the interface between the vascular wall and the blood, regulates multiple functions such as maintenance of normal vascular tone, modulation of coagulation, and immune responses [1]. It is widely demonstrated that the exposure of endothelial cells to proinflammatory stressors results in the production of molecules correlated with a proadhesive, prothrombotic, and proinflammatory phenotype that contributes to vascular disorders $[2,3]$, including cardiovascular diseases (CVDs).

Since ancient times, the extracts from the oleo-gum resin of Boswellia serrata Roxb. ex Colebr. (family Burseraceae), also identified as Indian frankincense or Salai Guggal, have been used in traditional Ayurvedic medicine for the treatment of inflammatory diseases, including osteoarthritis and chronic bowel diseases [4-8].

The oleo-gum resin, obtained by incision of the bark, is composed by essential oil (5-9\%), mucopolysaccarides
(21-22\%), and pure resin (65-85\%), containing tetracyclic and pentacyclic triterpene acids, of which boswellic acids (BAs) are the most important bioactive molecules $[4,9,10]$. In particular, 11-keto- $\beta$-boswellic acid (KBA) and 3-O-acetyl-11-keto- $\beta$-boswellic acid (AKBA) were proposed to act as inhibitors of 5-lipoxygenase (5-LO) [11, 12]. Recently, other components of the phytocomplex, such as $\beta$-boswellic acid $(\beta \mathrm{BA})$, have been suggested as anti-inflammatory molecules, acting through inhibition of serine protease cathepsin $\mathrm{G}$ (catG) and microsomal prostaglandin E synthase (mPGES) [9].

Differences in the relative amount of BAs and other components of the phytocomplex are related to the existence of different species of the genus Boswellia, to environmental conditions (e.g., soil composition, season, and air humidity), and to the extraction procedure [13] leading to herbal products of different composition and quality. In a previous study, seven $B$. serrata extracts were compared for their AKBA content and antioxidant power, highlighting wide variations 
[14]. In particular, one of the extracts obtained by bioliquefaction based on enzyme biocatalysis (hydroenzymatic extract) [15] showed interesting peculiarities. A lower content of AKBA and antioxidant power but higher activity in ex vivo tests on peripheral blood mononuclear cells (PBMCs) was determined in comparison with the dry extract [14]. In recent years, attention has also been focused on the role of other BAs, namely, KBA and $\beta$ BA $[16,17]$, suggesting a possible pharmacological activity also for these BAs. Preliminary data showed wide variability in the concentration of BAs in different extracts [18]; therefore, the present research is aimed at deepening the chemical characterization of the two extracts previously studied, focusing on HPLC quantification of KBA and $\beta$ BA. The effect of different formulations will be evaluated in comparison with the individual pure BAs in an interesting in vitro model: primary culture of porcine aortic endothelial cells (pAECs). With pig as an excellent model for translational medicine in the cardiovascular field $[19,20]$, we have previously isolated and cultured endothelial cells from thoracic aortas [21]. These primary cultures maintain a stable phenotype, and they prove to be an excellent model of study for the vascular response to different stressors $[22,23]$. Therefore, pAECs were chosen as an ideal in vitro model to study the anti-inflammatory and angiogenic properties of the two B. serrata extracts in comparison with pure $\mathrm{AKBA}, \mathrm{KBA}$, and $\beta \mathrm{BA}$, either individually or mixed together.

\section{Materials and Methods}

2.1. Chemicals and Reagents. Human endothelial SFM medium, heat-inactivated fetal bovine serum (FBS), antibiotic-antimycotic, and Dulbecco's phosphate-buffered saline (DPBS) were purchased from Gibco-Life technologies (Carlsbad CA, USA). Dimethyl sulfoxide (DMSO), trypsin EDTA solution, lipopolysaccharide (LPS) (E. coli 055: B5), glycerol, methanol, phosphoric acid, acetonitrile, and AKBA (batch number BCBN2928V and CAS number 67416-61-9) were purchased from Sigma-Aldrich Co. (St Louis, MO, USA). KBA and $\beta B A$ (batch numbers 15020106 and 15010405 and CAS numbers 17019-92-0 and 631-69-6, resp.) were obtained from PhytoPlan (Heidelberg, Germany). Six out of seven samples (extracts A-F) are dry extracts of $B$. serrata oleo-gum resin. The powder is insoluble in water but soluble in methanol and dimethyl sulfoxide (DMSO). Extract G is an aqueous extract obtained by a process of bioliquefaction based on enzyme biocatalysis [15]. Briefly, the gum resin from $B$. serrata was suspended in water $(1: 10 \mathrm{w} / \mathrm{v})$ and subjected to enzymatic digestion by xylanase, $\alpha$-amylase, and glucosidase for 24 hours. One $\mathrm{ml}$ of hydroenzymatic extract is obtained from $145 \mathrm{mg}$ of $B$. serrata resin ( $145 \mathrm{mg}$ resin/ml).

2.2. Qualitative and Quantitative Characterization of $B$. serrata Extracts. Qualitative and quantitative analyses of $B$. serrata extracts were performed by a reversed-phase highperformance liquid chromatography (HPLC) method using the HPLC system (Beckman Coulter, Brea, CA, USA), comprising a 116 pump, a 507 automatic autosampler, a UVDiode Array 168 detector, and integration software 32 Karat as reported by Beghelli et al. [14]. Seven samples (A-G) were analyzed for $\mathrm{KBA}$ and $\beta \mathrm{BA}$ concentrations and were prepared by dissolving extracts in methanol. KBA and $\beta \mathrm{BA}$ standard stock solutions were prepared by dissolving $5 \mathrm{mg}$ of analytical standard in methanol $(5 \mathrm{~mL})$. The calibration curves were obtained by analyzing six serial dilutions (50 ppm, $25 \mathrm{ppm}, 10 \mathrm{ppm}, 5 \mathrm{ppm}, 2.5 \mathrm{ppm}$, and $1 \mathrm{ppm}$ ) of the stock solution and by plotting the peak area measured at $260 \mathrm{~nm}$ against $\mathrm{KBA}$ concentrations and at $210 \mathrm{~nm}$ against $\beta \mathrm{BA}$ concentrations. The following equations of the curves were obtained:

$$
\begin{aligned}
\mathrm{KBA} & =77361 x+44918, r^{2}=0.999, \\
\beta \mathrm{BA} & =26532 x+721.54, r^{2}=0.999 .
\end{aligned}
$$

The KBA and $\beta$ BA peaks in the samples were identified on the basis of the retention time on the chromatogram at $260 \mathrm{~nm}$ and $210 \mathrm{~nm}$, respectively. All measurements were performed in triplicate and data were reported as mean \pm SD.

2.3. Cell Culture and Treatment. Porcine aortic endothelial cells (pAECs) were isolated and maintained as previously described by Bernardini et al. [21]. All experiments were performed with cells from the third to the eighth passage. The first seeding after thawing was always performed in T-25 tissue culture flasks $\left(3 \times 10^{5}\right.$ cells/flask) (T-25, BD Falcon, Franklin Lakes, NJ, USA), and successive experiments were conducted in 24-well plates (scratch test) or 96-well plates (cell viability) with confluent cultures. Cells were cultured in human endothelial SFM medium, added with FBS (5\%) and antimicrobial/antimycotic solution (1x) in a $5 \% \mathrm{CO}_{2}$ atmosphere at $38.5^{\circ} \mathrm{C}$. Extract A was dissolved in DMSO at $10 \mathrm{mg}$ dry extract $/ \mathrm{ml}$ (stock solution) and then diluted in culture medium to obtain four doses containing $0.1,1,10$, and $100 \mu \mathrm{g}$ of dry extract/ml, respectively. Extract G, which is an aqueous solution, was directly diluted in culture medium to obtain four doses referring to 2.4, 24, 240, and $2400 \mu \mathrm{g}$ of $\mathrm{resin} / \mathrm{ml}$. These doses were chosen and normalized on the basis of AKBA concentration in extracts as reported in [14]: for both extracts, the lowest dose contained $3.8 \mathrm{ng} / \mathrm{ml}$ of AKBA and the highest dose contained $3.8 \mu \mathrm{g} / \mathrm{ml}$ of AKBA.

Pure analytical grade BAs (KBA, AKBA, and $\beta B A$ ) were dissolved in methanol (stock solution $1 \mathrm{mg} / \mathrm{ml}$ ) and then in culture medium to obtain the required concentrations. Two

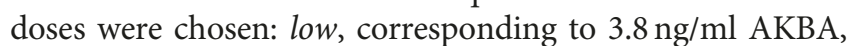
$3 \mathrm{ng} / \mathrm{ml} \mathrm{KBA}$, and $8 \mathrm{ng} / \mathrm{ml} \beta \mathrm{BA}$, and high, corresponding to $380 \mathrm{ng} / \mathrm{ml} \mathrm{AKBA}, 300 \mathrm{ng} / \mathrm{ml} \mathrm{KBA}$, and $800 \mathrm{ng} / \mathrm{ml} \beta B$. For each treatment, the same concentration of the specific vehicle was used as control.

2.4. Effect of B. serrata Extracts on pAEC Viability. pAECs were seeded in a 96 -well plate $\left(6 \times 10^{3}\right.$ cells/well $)$ and exposed to four increasing doses of $B$. serrata extracts for $24 \mathrm{~h}$. Cell viability was measured using tetrazolium salt (MTT assay). The formazan absorbance was measured at a wavelength of $570 \mathrm{~nm}$, using Infinite ${ }^{\circledR}$ F50/Robotic absorbance microplate readers from TECAN (Life Sciences). The background absorbance of multiwell plates at $690 \mathrm{~nm}$ was also measured and subtracted from the $570 \mathrm{~nm}$ measurements. 
2.5. Effect of B. serrata Extracts on LPS-Induced pAEC Death. pAECs seeded in a 96-well plate $\left(6 \times 10^{3} \mathrm{cells} / \mathrm{cm}^{2}\right)$ were exposed to lipopolysaccharide (LPS) $(25 \mu \mathrm{g} / \mathrm{ml})$ for $24 \mathrm{~h}$ either in the presence or in the absence of extracts A and G or pure BAs at the concentrations reported above. Cell viability was evaluated by MTT assay.

2.6. Effect of B. serrata Extracts on pAEC Migration Capacity. pAECs were seeded in a 24 -well plate $\left(4 \times 10^{4}\right.$ cells/well). When cells reached confluence, a wound was induced scratching the surface by a pipette tip, then the detached cells were removed by washing with DPBS. Complete medium containing low and high doses of extract A $(0.1 \mu \mathrm{g}$ dry extract $/ \mathrm{ml}$ and $10 \mu \mathrm{g}$ dry extract $/ \mathrm{ml}$ ) and extract G $(2.4 \mu \mathrm{g}$ resin $/ \mathrm{ml}$ and $240 \mu \mathrm{g}$ resin $/ \mathrm{ml}$ ) and pure BAs at low ( $3 \mathrm{ng} / \mathrm{ml} \mathrm{KBA}, 3.8 \mathrm{ng} / \mathrm{ml} \mathrm{AKBA}$, and $8 \mathrm{ng} / \mathrm{ml} \beta \mathrm{BA}$ ) and high $(300 \mathrm{ng} / \mathrm{ml} \mathrm{KBA}, 380 \mathrm{ng} / \mathrm{ml} \mathrm{AKBA}$, and $800 \mathrm{ng} / \mathrm{ml} \beta \mathrm{BA})$ concentrations were added. Microscopic phase-contrast pictures and three measurements of the damaged areas were taken immediately after the scratches (T0) and after $6 \mathrm{~h}$ (T1) and $24 \mathrm{~h}$ (T2). Images were acquired using a Nikon epifluorescence microscope equipped with digital camera (Nikon, Yokohama, Japan).

2.7. Statistical Analysis. Each treatment was replicated three times (migration capacity) or eight times (cell viability and LPS challenge). Data were analyzed with a one-way analysis of variance (ANOVA) followed by the Tukey post hoc comparison test or Student's $t$-test. Differences of at least $p<0.05$ were considered significant. Statistical analysis was carried out using R software (http://www.R-project.org).

\section{Results}

3.1. KBA and $\beta B A$ Quantification by HPLC-DAD Analysis. Representative chromatograms of KBA, AKBA, and $\beta B A$ analytical standards as well as extracts A and G analyzed at 210 and $260 \mathrm{~nm}$ are reported in Figure 1.

Both extracts presented two major peaks at $260 \mathrm{~nm}$ : the first one, at Rt of 13.2 min, identified as KBA by the use of the analytical standard, and the second one, at Rt of $26 \mathrm{~min}$, previously identified as AKBA. Other components of the $B$. serrata phytocomplex were only visualized at $210 \mathrm{~nm}$, and the peak at Rt of 49 min was identified as $\beta B A$ by the use of the analytical standard. KBA, AKBA, and $\beta$ BA concentrations, calculated based on the peak area and the calibration curve, are shown in Table 1.

Quantitative and qualitative differences were present. The concentrations of BAs in extract $G$ were two orders of magnitude lower than in extract $\mathrm{A}$, and the chromatogram of extract $G$ was characterized by a major number of peaks resolved at $210 \mathrm{~nm}$. Data on KBA and $\beta B A$ concentrations in other additional five dry extracts $(\mathrm{B}-\mathrm{F})$ are reported in Table S1 in the Supplementary Material.

3.2. Effect of B. serrata Extracts on pAEC Viability. Extract A was cytotoxic at higher concentrations, resulting in a reduction in cell viability of 12 and $47 \%$, respectively, while lower concentrations did not affect cell viability (Figure 2(a)). Extract G did not show any toxic effect on
pAECs (Figure 2(b)). In the presence of pure BAs, a significant $(p<0.05)$ cytotoxic effect was detected at the concentrations studied (Figure 2(c)). Only AKBA presented a dose-dependent effect.

3.3. Effect of B. serrata Extracts on LPS-Induced PAEC Death. LPS challenge determined a significant $30 \%$ reduction of cell viability. Extract A significantly $(p<0.05)$ reduced the cytotoxicity induced by LPS at the lower concentrations (Figure 3(a)). The highest concentration elicited a significant exacerbation of LPS cytotoxicity resulting in 70\% reduction of cell viability, while the lowest concentration showed a significant proliferative effect, resulting in a $40 \%$ increase in cell viability. Extract $G$ significantly $(p<0.05)$ restored pAEC viability after LPS treatment at all the concentrations analyzed (Figure 3(b)), without a dose-dependent effect. None of pure BAs, individually or mixed together, was able to contrast LPS cytotoxicity (Figure 3(c)).

3.4. Effect of B. serrata Extracts on pAEC Migration Capacity. Extract A reduced the damaged area at T1 $(6 \mathrm{~h})$ and restored completely the monolayer at T2 $(24 \mathrm{~h})$ at the lower concentration, while at $10 \mu \mathrm{g}$ dry extract $/ \mathrm{ml}$ no significant effect on cell proliferation was measured (Figure 4(a)). The incubation with extract $G$ did not determine the recovery of the damage (Figure 4(b)). Pure BAs showed a significant wound-healing effect at the end of the incubation at the lower concentration (Figure 4(c)). In particular, AKBA at $3.8 \mathrm{ng} / \mathrm{ml}$ completely restored the monolayer.

\section{Discussion}

The gum resin obtained from B. serrata, used in Ayurvedic medicine for the treatment of a variety of diseases, is considered a promising natural source of anti-inflammatory molecules, in particular BAs $[4,9]$.

The quantification of these active molecules is a prerequisite for testing any biological effect of a phytoextract from $B$. serrata. Therefore, the first aim of this study was to better characterize the $\mathrm{BA}$ profile through the quantification of $\mathrm{KBA}$ and $\beta \mathrm{BA}$ in addition to AKBA. The concentrations of $\mathrm{BAs}$ determined in extract $\mathrm{A}$ are in the range of those reported by other authors [24-26]. AKBA and KBA are used as markers to ensure the quality of $B$. serrata dry extracts, but their concentrations show wide variability in commercial products, which in general claim $65 \%$ of BAs. In general, BAs represent only a percentage of total organic acids, whose concentrations are determined by unspecific titration methods and, as a consequence, the claimed content of $65 \%$ BAs is absolutely unrealistic as recently pointed out also by other authors [24, 25]. Very low percentages of $\mathrm{KBA}$ and $\beta \mathrm{BA}$ were found in extract $\mathrm{G}$ compared to extract $A$. This aqueous extract was also characterized by low AKBA and low polyphenol concentrations [14], confirming again the importance of the extraction procedure on the phytocomplex composition.

To evaluate the possible biological effects of these different formulations, extracts $A$ and $G$, normalized on the basis of AKBA content, were used for in vitro analyses to assess 


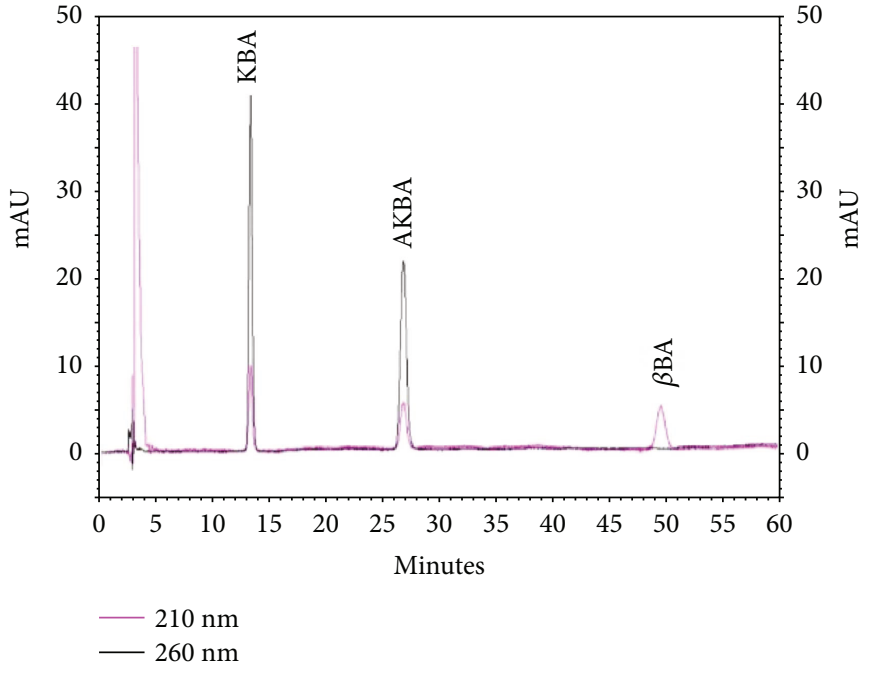

(a)

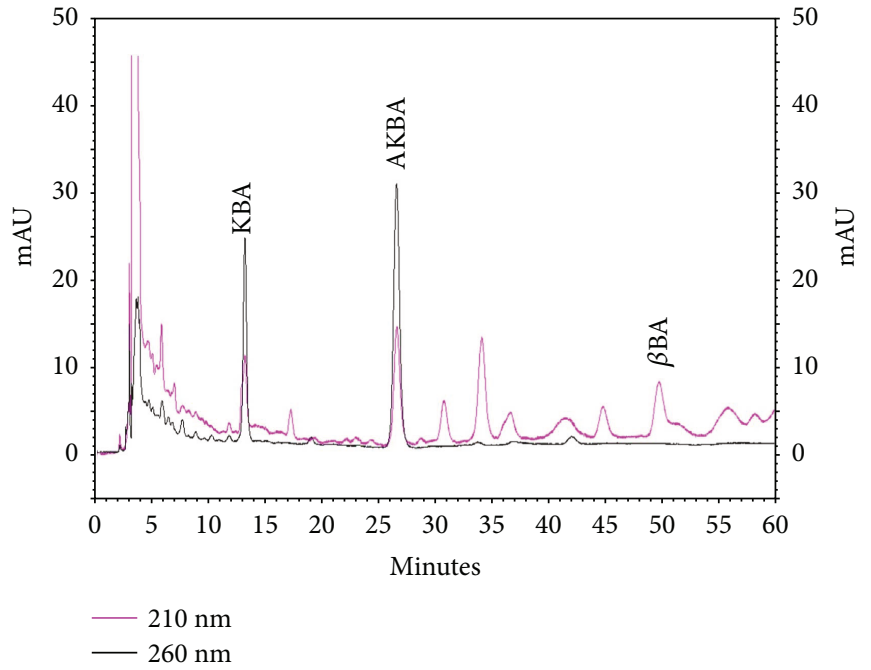

(b)

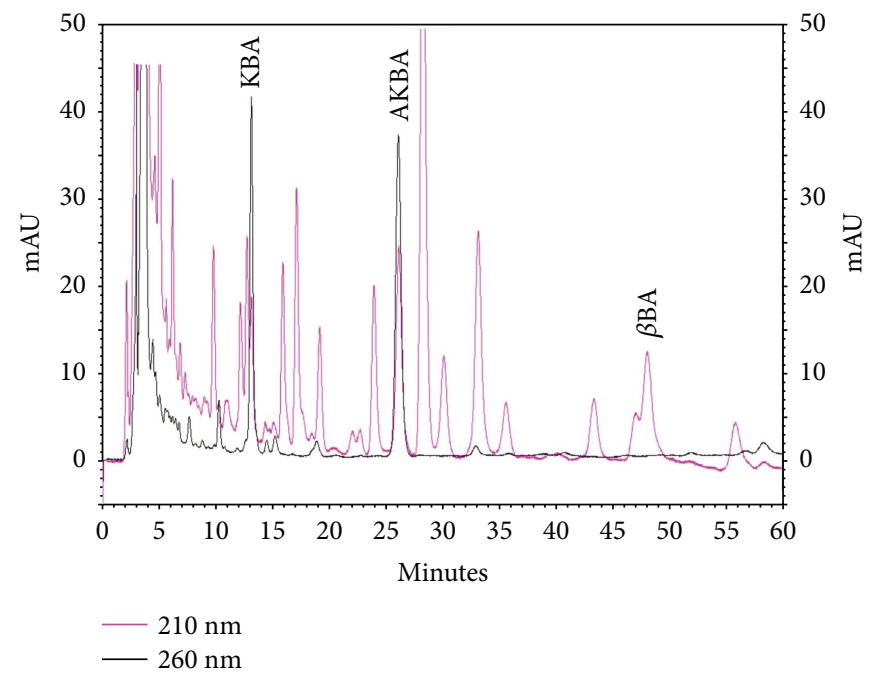

(c)

FIGURE 1: Representative chromatograms of pure analytical grade BAs (KBA, AKBA, and $\beta B A$ ) (25 ppm each) (a), extract A (b), and extract G (c) at 210 (pink chromatogram) and $260 \mathrm{~nm}$ (black chromatogram).

TABLE 1: KBA, $\beta B A$, and AKBA quantification in Boswellia serrata extracts. Data are reported as mean $\pm \mathrm{SD}(n=3)$. Concentration is expressed in $\mathrm{mg} / \mathrm{g}$ of dry extract (extract A) or $\mathrm{mg} / \mathrm{ml}$ of hydroenzymatic extract (extract G). For each BA, significant differences between extracts are indicated by * $(p<0.05$, Student's $t$-test) and by ${ }^{* *}(p<0.001$, Student's $t$-test $)$.

\begin{tabular}{lccc}
\hline Extract & $\mathrm{KBA}^{\S}$ & $\beta \mathrm{BA}$ & $\mathrm{AKBA}^{\S}$ \\
\hline $\mathrm{A}$ & $15.86 \pm 0.56^{* *}$ & $33.53 \pm 7.23^{*}$ & $38.30 \pm 1.01^{* *}$ \\
$\mathrm{G}$ & $0.19 \pm 0.02$ & $0.50 \pm 0.03$ & $0.29 \pm 0.04$ \\
\hline
\end{tabular}

${ }^{\mathrm{s}}$ Data of AKBA concentrations are reported in Beghelli et al. [14].

cytotoxicity, anti-inflammatory activity, and angiogenic properties in comparison with pure BAs. Cytotoxic effects of B. serrata dry extracts and BAs were reported in several studies in different cancer cell lines, such as leukemia cells, prostate cancer cells, and gastrointestinal cancer cells $[7,27-30]$. As regards the biochemical mechanism of cell death, Liu et al. [31] reported that BAs are able to induce apoptosis in Hep-G2 cells through the activation of caspase-8, while Bhushan et al. [32] found that a triterpendiol derived from BAs induced apoptosis in HL-60 cells through the activation of Bcl-2 and caspase-3.

The anti-inflammatory activity of Boswellia extracts was demonstrated in microvascular endothelial cells by preventing $\mathrm{TNF} \alpha$-induced expression and activity of MMP-3, MMP-10, and MMP-12 [33]. Moreover, previous studies have shown that $B$. serrata extracts and BAs antagonize the inflammatory effect of LPS in human and mouse macrophages, monocytes, and PBMCs [34-36]. Our results demonstrated for the first time the protective effect of $B$. serrata extracts against LPS inflammatory stimulus in endothelial cells. In particular, extract $G$ was the most effective, restoring completely cell viability at all the doses studied without any cytotoxicity. On the contrary, increasing concentrations of extract A lead to opposite results ranging 


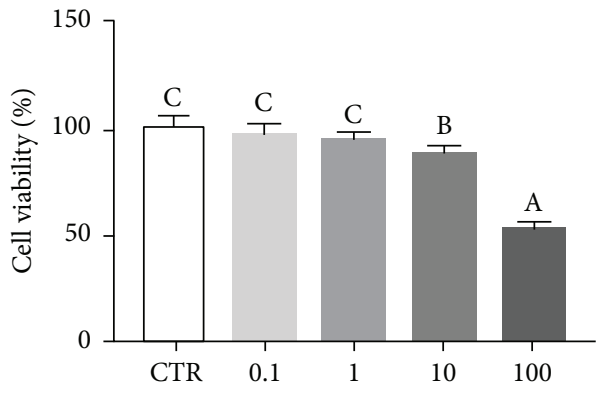

(a)

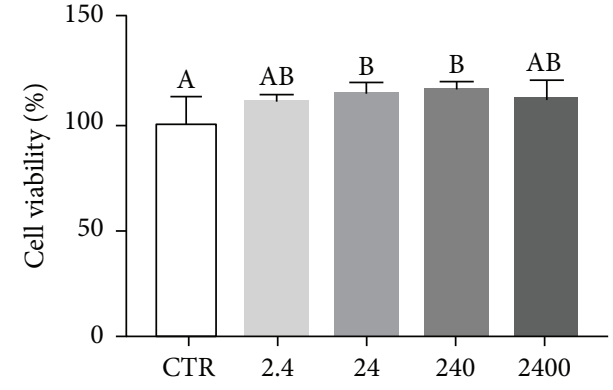

(b)

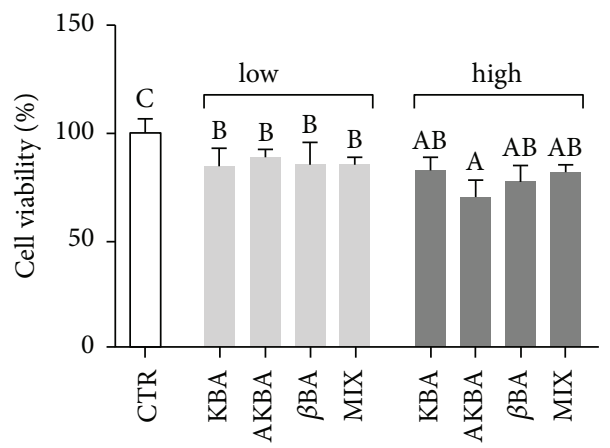

(c)

Figure 2: Effect of increasing doses of $B$. serrata extract A $(0.1,1,10$, and $100 \mu \mathrm{g}$ dry extract/ml) (a), extract G $(2.4,24,240$, and $2400 \mu \mathrm{g}$ $\mathrm{resin} / \mathrm{ml}$ ) (b), and pure BAs (low, corresponding to $3.8 \mathrm{ng} / \mathrm{ml} \mathrm{AKBA,} 3 \mathrm{ng} / \mathrm{ml} \mathrm{KBA}$, and $8 \mathrm{ng} / \mathrm{ml} \beta \mathrm{BA}$, and high, corresponding to $380 \mathrm{ng} / \mathrm{ml}$ $\mathrm{AKBA}, 300 \mathrm{ng} / \mathrm{ml} \mathrm{KBA}$, and $800 \mathrm{ng} / \mathrm{ml} \beta \mathrm{BA}$ ) (c) on pAECs. Cell viability was measured by MTT assay. Data are reported as mean \pm SD of 8 independent replicates. Different letters above the bars indicate significant differences $(p<0.05$ ANOVA post hoc Tukey's test).

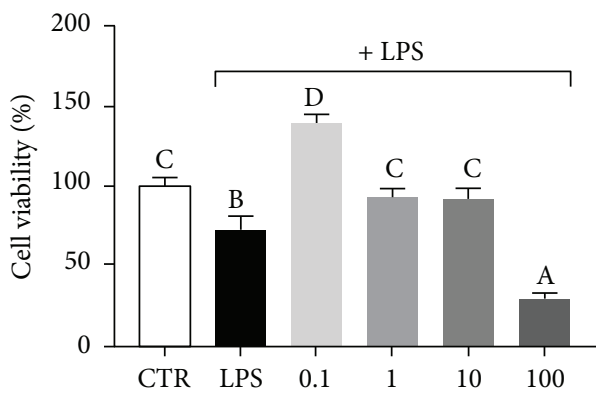

(a)

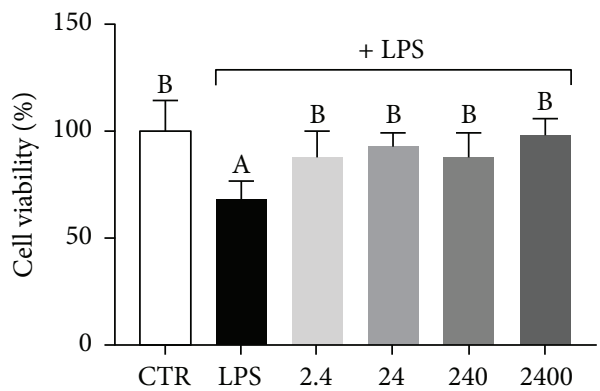

(b)

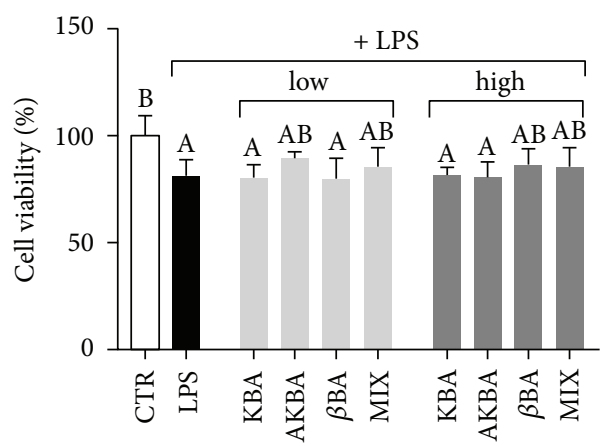

(c)

FIGURE 3: Effect of increasing doses of $B$. serrata extract A $(0.1,1,10$, and $100 \mu \mathrm{g}$ dry extract/ml) (a), extract G (2.4, 24, 240, and 2400 $\mu \mathrm{g}$ resin/ml) (b), and pure BAs (low, corresponding to $3.8 \mathrm{ng} / \mathrm{ml} \mathrm{AKBA,} 3 \mathrm{ng} / \mathrm{ml} \mathrm{KBA}$, and $8 \mathrm{ng} / \mathrm{ml} \beta \mathrm{BA}$, and high, corresponding to $380 \mathrm{ng} / \mathrm{ml} \mathrm{AKBA}, 300 \mathrm{ng} / \mathrm{ml} \mathrm{KBA}$, and $800 \mathrm{ng} / \mathrm{ml} \beta \mathrm{BA}$ ) (c) on pAEC viability, in the presence of LPS ( $25 \mu \mathrm{g} / \mathrm{ml})$, measured by MTT assay. Data are reported as mean \pm SD of 8 independent replicates. Different letters above the bars indicate significant differences $(p<0.05$ ANOVA post hoc Tukey's test). 

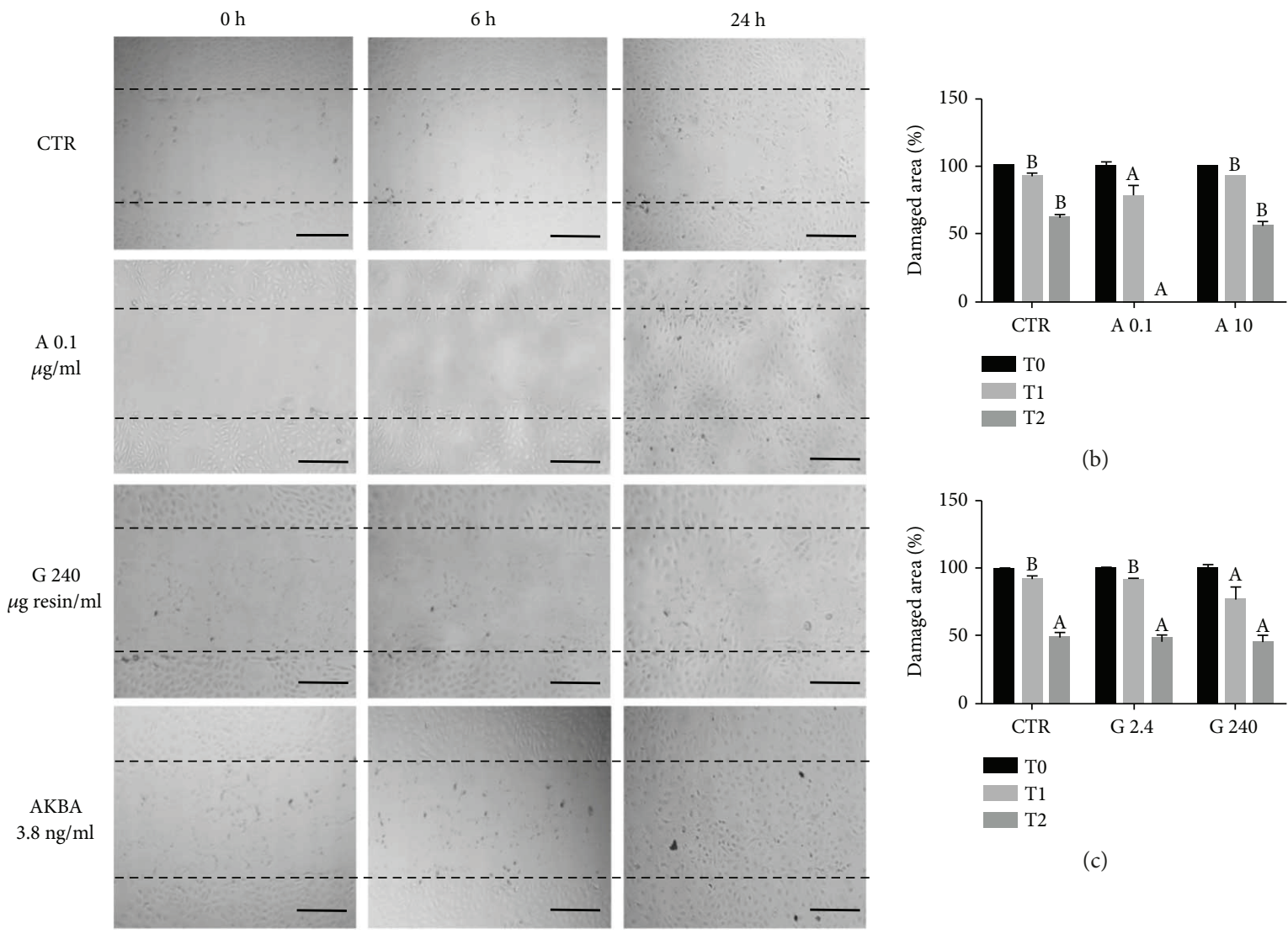

(b)

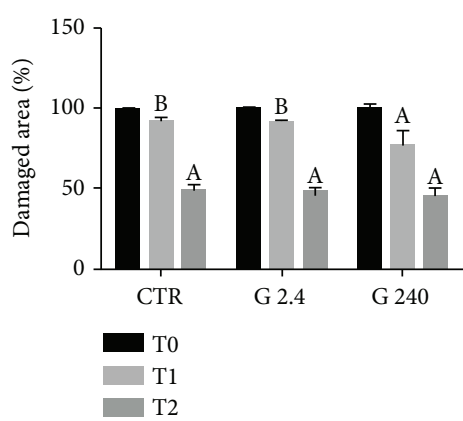

(c)

(a)

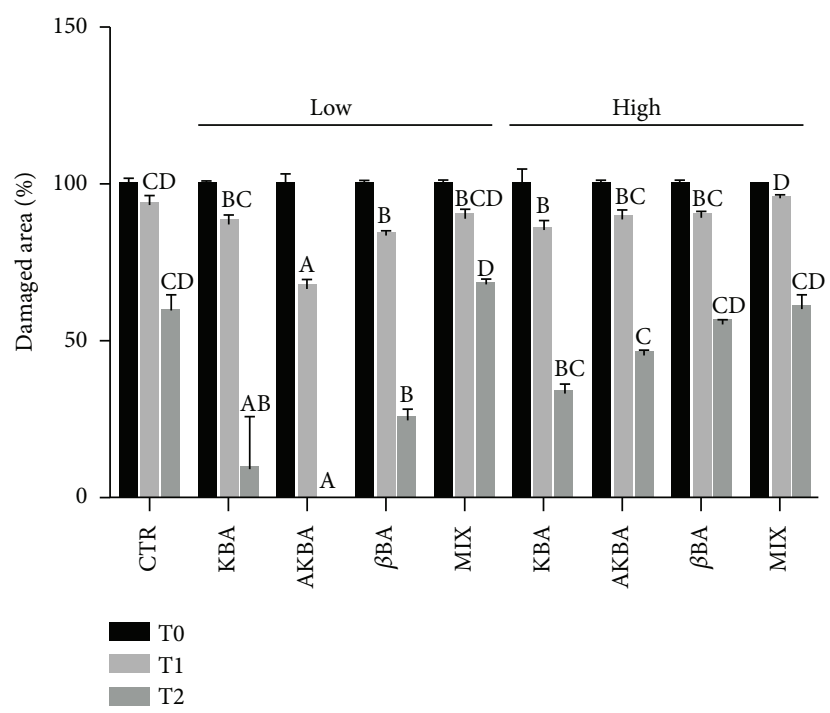

(d)

FIGURE 4: Effect of B. serrata extracts on pAEC migration capacity. Cells were scratch wounded and then treated with extracts A and G and

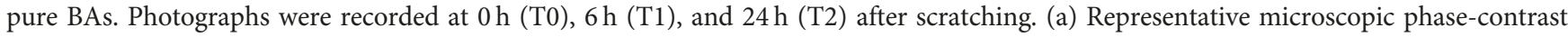
pictures showing the size of the scratch wound in different treatment groups compared with control. Scale bar, $200 \mu \mathrm{m}$. The extent of the damaged area (\%) is reported for treatment with extract A (0.1 and $10 \mu \mathrm{g}$ dry extract $/ \mathrm{ml})(\mathrm{b})$, extract G (2.4 and $240 \mu \mathrm{g}$ resin/ml) (c), and pure BAs (low, corresponding to $3 \mathrm{ng} / \mathrm{ml} \mathrm{KBA}, 3.8 \mathrm{ng} / \mathrm{ml} \mathrm{AKBA}$, and $8 \mathrm{ng} / \mathrm{ml} \beta \mathrm{BA}$, and high, corresponding to $300 \mathrm{ng} / \mathrm{ml} \mathrm{KBA,} 380 \mathrm{ng} / \mathrm{ml}$ $\mathrm{AKBA}$, and $800 \mathrm{ng} / \mathrm{ml} \beta \mathrm{BA})(\mathrm{d})$. Data are reported as mean of 3 replicates \pm SD. Inside each experimental time (T1 and T2), different letters above the bars indicate significant differences among treatments ( $p<0.05$, ANOVA post hoc Tukey's test). 
from hyperproliferative effect (the lowest dose) to cytotoxic effect (the highest dose). Interestingly, in our model the use of pure $\mathrm{KBA}, \beta \mathrm{BA}$, and $\mathrm{AKBA}$, either individually or mixed together, failed to protect endothelial cells from LPS toxicity and are only partially in accord with data reported by Henkel et al. [35]. In a cell-free assay, those authors suggested a direct molecular interaction between LPS and $\mathrm{BAs}$ lacking the keto moiety, in particular $\beta \mathrm{BA}$, underlying the anti-inflammatory effect of Boswellia extracts.

Our results support the hypothesis that the antiinflammatory effect of Boswellia extracts is not strictly dependent on the presence of the most studied BAs, but it can be related to other bioactive molecules. Other triterpenes, as incensole, could be considered interesting candidates for the pharmacological properties of frankincense, accordingly to suggestions previously reported by other authors $[9,37,38]$. Beyond these bioactive terpenes, the gum resin does contain polysaccharides. These molecules are likely to be minor components in dry extract $\mathrm{A}$, whereas they can be more concentrated in extract $G$, due to the different polarity of the extraction medium. A water-soluble fraction extracted from the gum resin of $B$. serrata containing galactose, arabinose, and D-glucuronic acid was suggested to act as a potent enhancer of humoral and cellmediated immune response [39], while the potential antiinflammatory activity of these polysaccharides has not yet been explored. We cannot exclude that the polysaccharide fraction present in extract $G$ can develop additional modulatory effects on pAECs.

The migration ability of endothelial cells is critical in the physiological and pathological angiogenesis [40]. Our results obtained with an in vitro model of physiological angiogenesis showed proangiogenic activity of extract A at the lowest concentration, in agreement with a proliferative effect of the same dose recorded in LPS challenge. In addition, incubation with pure AKBA at the same concentration as that measured in extract A determined the same proangiogenic effect, indicating a possible involvement of this $\mathrm{BA}$ in promoting angiogenesis. In contrast, incubation in the presence of extract $G$ containing the same concentrations of AKBA did not show any effect on endothelial cell migration capacity, indicating one more time the existence of complex molecular interactions, which can modify the biological effect of the phytoextract. Contrasting results are also reported in literature. Lulli et al. [41] observed that AKBA reduced proliferation, migration, and tube formation in human retinal microvascular endothelial cells (HRMECs) stimulated with exogenous vascular endothelial growth factor (VEGF). On the other hand, Wang et al. [17] reported that $\beta$-BA can attenuate endothelial cell injury in a blood stasis model and protect human umbilical vein endothelial cells (HUEVCs) against cell death induced by oxygen and glucose deprivation. Different regulation pathways could be involved in the repairing activity of Boswellia extracts, and further investigations will be necessary to explain why different formulations determine different effects on endothelial cells pathophysiology.

How extracts of $B$. serrata gum resin should modulate the cardiovascular system has been scarcely investigated, so far. Kokkiripati et al. [42] reported that antioxidant and antithrombotic activities of extracts from B. serrata gum resin determined the inhibition of human monocytic cell activation and platelet aggregation. However, recently Siemoneit et al. [43] pointed out the complex agonizing and antagonizing effects of BAs on human platelet aggregation and prompted for careful evaluation of $B$. serrata extract safety in cardiovascular disease-risk patients.

In conclusion, our results demonstrate that different formulations (e.g., dry and hydroenzymatic extracts) obtained from the same botanical species show significantly different biological effects on endothelial cells. The antiinflammatory activity of $B$. serrata extracts on endothelial cells suggests a potential pharmaceutical application for cardiovascular health, though cytotoxicity or proliferative stimulation can occur instead of a protective effect, depending on the dose and the formulation. This aspect should be carefully considered when these herbal products are used in human and animal phytotherapy.

\section{Disclosure}

Preliminary data has been presented as a poster at the 21th Congress Phytopharm 2017, Graz, Austria, 2-5 July 2017.

\section{Conflicts of Interest}

The authors declare that there is no conflict of interest regarding the publication of this paper.

\section{Acknowledgments}

The authors greatly acknowledge Phenbiox Srl (Calderara di Reno, Bologna, Italy) and Dr. Maurizio Scozzoli for providing the Boswellia serrata hydroenzymatic and dry extracts, respectively, and Dr. Alberto Altafini for technical assistance. The authors are grateful to Università di Bologna and Fondazione Cassa di Risparmio di Imola for their financial support.

\section{Supplementary Materials}

Table S1: the concentrations of the two boswellic acids analyzed and discussed in the manuscript in five additional dry extracts of Boswellia serrata. The table has been added to emphasize the variability of boswellic acid concentration in different dry extracts obtained from the same botanical species. (Supplementary Materials)

\section{References}

[1] W. C. Aird, "Endothelium and haemostasis," Hämostaseologie, vol. 35, no. 1, pp. 11-16, 2015.

[2] T. Aki, N. Egashira, M. Hama et al., "Characteristics of gabexate mesilate-induced cell injury in porcine aorta endothelial cells," Society, vol. 106, no. 3, pp. 415-422, 2008.

[3] S. Jamwal and S. Sharma, "Vascular endothelium dysfunction: a conservative target in metabolic disorders," Inflammation Research, vol. 67, no. 5, pp. 391-405, 2018.

[4] H. P. T. Ammon, "Boswellic acids in chronic inflammatory diseases," Planta Medica, vol. 72, no. 12, pp. 1100-1116, 2006. 
[5] H. P. T. Ammon, "Boswellic acids and their role in chronic inflammatory diseases," in Anti-Inflammatory Nutraceuticals and Chronic Diseases, S. C. Gupta, S. Prasad, and B. B. Aggarwal, Eds., pp. 291-327, Cham: Springer International Publishing, Switzerland, 2016.

[6] I. Gupta, A. Parihar, P. Malhotra et al., "Effects of gum resin of Boswellia serrata in patients with chronic colitis," Planta Medica, vol. 67, no. 5, pp. 391-395, 2001.

[7] M. A. Khan, R. Ali, R. Parveen, A. K. Najmi, and S. Ahmad, "Pharmacological evidences for cytotoxic and antitumor properties of Boswellic acids from Boswellia serrata," Journal of Ethnopharmacology, vol. 191, pp. 315-323, 2016.

[8] K. Sengupta, K. V. Alluri, A. Satish et al., "A double blind, randomized, placebo controlled study of the efficacy and safety of 5-Loxin ${ }^{\circledR}$ for treatment of osteoarthritis of the knee," Arthritis Research \& Therapy, vol. 10, no. 4, article R85, 2008.

[9] M. Abdel-Tawab, O. Werz, and M. Schubert-Zsilavecz, "Boswellia serrata," Clinical Pharmacokinetics, vol. 50, no. 6, pp. 349-369, 2011.

[10] A. R. M. Al-Yasiry and B. Kiczorowska, "Frankincense - therapeutic properties," Postępy Higieny i Medycyny Doświadczalnej, vol. 70, pp. 380-391, 2016.

[11] H. P. T. Ammon, "Modulation of the immune system by Boswellia serrata extracts and boswellic acids," Phytomedicine, vol. 17, no. 11, pp. 862-867, 2010.

[12] H. Hussain, A. Al-Harrasi, R. Csuk et al., "Therapeutic potential of boswellic acids: a patent review (1990-2015)," Expert Opinion on Therapeutic Patents, vol. 27, no. 1, pp. 81-90, 2017.

[13] M. Gupta, P. K. Rout, L. N. Misra et al., "Chemical composition and bioactivity of Boswellia serrata Roxb. essential oil in relation to geographical variation," Plant Biosystems - An International Journal Dealing with all Aspects of Plant Biology, vol. 151, no. 4, pp. 623-629, 2017.

[14] D. Beghelli, G. Isani, P. Roncada et al., "Antioxidant and ex vivo immune system regulatory properties of Boswellia serrata extracts," Oxidative Medicine and Cellular Longevity, vol. 2017, Article ID 7468064, 10 pages, 2017.

[15] L. Setti and D. Zanichelli, "Bioliquefaction as a biorefinery's approach for the production of natural bioactive compounds for functional cosmetics," in Waste Recovery: Strategies, Techniques and Applications in Europe, L. Morselli, F. Passarini, and I. Vassura, Eds., pp. 122-128, Franco Angeli, Milan, Italy, 2009.

[16] Y. Ding, M. Chen, M. Wang, Y. Li, and A. Wen, "Posttreatment with 11-keto- $\beta$-boswellic acid ameliorates cerebral ischemia-reperfusion injury: $\mathrm{Nrf2/HO}-1$ pathway as a potential mechanism," Molecular Neurobiology, vol. 52, no. 3, pp. 1430-1439, 2015.

[17] M. Wang, M. Chen, Y. Ding et al., "Pretreatment with $\beta$ boswellic acid improves blood stasis induced endothelial dysfunction: role of eNOS activation," Scientific Reports, vol. 5, no. 1, article 15357, 2015.

[18] M. Bertocchi, F. Medici, C. Bernardini et al., "Characterization of Boswellia serrata extracts and evaluation of their effects on porcine aortic endothelial cells," in Reviews on Clinical Pharmacology and Drug Therapy (The 21th International Congress Phytopharm 2017), vol. 15, p. 42, Graz, Austria, July 2017.

[19] C. Zaragoza, C. Gomez-Guerrero, J. L. Martin-Ventura et al., "Animal models of cardiovascular diseases," Journal of Biomedicine \& Biotechnology, vol. 2011, Article ID 497841, 13 pages, 2011.
[20] C. Perleberg, A. Kind, and A. Schnieke, "Genetically engineered pigs as models for human disease," Disease Models \& Mechanisms, vol. 11, no. 1, article dmm030783, 2018.

[21] C. Bernardini, A. Zannoni, M. E. Turba et al., "Heat shock protein 70 , heat shock protein 32, and vascular endothelial growth factor production and their effects on lipopolysaccharideinduced apoptosis in porcine aortic endothelial cells," Cell Stress \& Chaperones, vol. 10, no. 4, pp. 340-348, 2005.

[22] C. Bernardini, A. Zannoni, M. L. Bacci, and M. Forni, "Protective effect of carbon monoxide pre-conditioning on LPS-induced endothelial cell stress," Cell Stress and Chaperones, vol. 15, no. 2, pp. 219-224, 2010.

[23] G. Botelho, C. Bernardini, A. Zannoni, V. Ventrella, M. L. Bacci, and M. Forni, "Effect of tributyltin on mammalian endothelial cell integrity," Comparative Biochemistry and Physiology Part C: Toxicology \& Pharmacology, vol. 176-177, pp. 79-86, 2015.

[24] G. Mannino, A. Occhipinti, and M. Maffei, "Quantitative determination of 3-O-acetyl-11-keto- $\beta$-boswellic acid (AKBA) and other boswellic acids in Boswellia sacra Flueck (syn. B. carteri Birdw) and Boswellia serrata Roxb," Molecules, vol. 21, no. 10, p. 1329, 2016.

[25] J. Meins, C. Artaria, A. Riva, P. Morazzoni, M. SchubertZsilavecz, and M. Abdel-Tawab, "Survey on the quality of the top-selling European and American botanical dietary supplements containing boswellic acids," Planta Medica, vol. 82, no. 6, pp. 573-579, 2016.

[26] E. Ranzato, S. Martinotti, A. Volante, A. Tava, M. A. Masini, and B. Burlando, "The major Boswellia serrata active 3-acetyl-11-keto- $\beta$-boswellic acid strengthens interleukin- $1 \alpha$ upregulation of matrix metalloproteinase-9 via JNK MAP kinase activation," Phytomedicine, vol. 36, pp. 176-182, 2017.

[27] Y. Shao, C.-T. Ho, C.-K. Chin, V. Badmaev, W. Ma, and M.-T. Huang, "Inhibitory activity of boswellic acids from Boswellia serrata against human leukemia HL-60 cells in culture," Planta Medica, vol. 64, no. 4, pp. 328-331, 1998.

[28] M. Lu, L. Xia, H. Hua, and Y. Jing, "Acetyl-keto-B-boswellic acid induces apoptosis through a death receptor 5-mediated pathway in prostate cancer cells," Cancer Research, vol. 68, no. 4, pp. 1180-1186, 2008.

[29] J.-J. Liu, B. Huang, and S. C. Hooi, “Acetyl-keto- $\beta$-boswellic acid inhibits cellular proliferation through a p21-dependent pathway in colon cancer cells," British Journal of Pharmacology, vol. 148, no. 8, pp. 1099-1107, 2006.

[30] B. Park, S. Prasad, V. Yadav, B. Sung, and B. B. Aggarwal, "Boswellic acid suppresses growth and metastasis of human pancreatic tumors in an orthotopic nude mouse model through modulation of multiple targets," PLoS One, vol. 6, no. 10, article e26943, 2011.

[31] J.-J. Liu, A. Nilsson, S. Oredsson, V. Badmaev, and R.-D. Duan, "Keto- and acetyl-keto-boswellic acids inhibit proliferation and induce apoptosis in Hep G2 cells via a caspase-8 dependent pathway," International Journal of Molecular Medicine, vol. 10, no. 4, pp. 501-505, 2002.

[32] S. Bhushan, A. Kumar, F. Malik et al., "A triterpenediol from Boswellia serrata induces apoptosis through both the intrinsic and extrinsic apoptotic pathways in human leukemia HL-60 cells," Apoptosis, vol. 12, no. 10, pp. 1911-1926, 2007.

[33] S. Roy, S. Khanna, A. V. Krishnaraju et al., "Regulation of vascular responses to inflammation: inducible matrix metalloproteinase-3 expression in human microvascular endothelial cells is sensitive to antiinflammatory Boswellia," 
Antioxidants \& Redox Signaling, vol. 8, no. 3-4, pp. 653660, 2006.

[34] C. Cuaz-Perolin, L. Billiet, E. Bauge et al., "Antiinflammatory and antiatherogenic effects of the NF- $\kappa \mathrm{B}$ inhibitor acetyl-11keto- $\beta$-boswellic acid in LPS-challenged ApoE-/- mice," Arteriosclerosis, Thrombosis, and Vascular Biology, vol. 28, no. 2, pp. 272-277, 2008.

[35] A. Henkel, N. Kather, B. Mönch, H. Northoff, J. Jauch, and O. Werz, "Boswellic acids from frankincense inhibit lipopolysaccharide functionality through direct molecular interference," Biochemical Pharmacology, vol. 83, no. 1, pp. 115-121, 2012.

[36] T. Syrovets, B. Buchele, C. Krauss, Y. Laumonnier, and T. Simmet, "Acetyl-boswellic acids inhibit lipopolysaccharidemediated TNF- $\alpha$ induction in monocytes by direct interaction with I $\kappa$ B kinases," Journal of Immunology, vol. 174, no. 1, pp. 498-506, 2005.

[37] A. Moussaieff, E. Shohami, Y. Kashman et al., "Incensole acetate, a novel anti-inflammatory compound isolated from Boswellia resin, inhibits nuclear factor $-\kappa \mathrm{B}$ activation," Molecular Pharmacology, vol. 72, no. 6, pp. 1657-1664, 2007.

[38] B. Gayathri, N. Manjula, K. S. Vinaykumar, B. S. Lakshmi, and A. Balakrishnan, "Pure compound from Boswellia serrata extract exhibits anti-inflammatory property in human PBMCs and mouse macrophages through inhibition of TNF $\alpha$, IL- $1 \beta$, NO and MAP kinases," International Immunopharmacology, vol. 7, no. 4, pp. 473-482, 2007.

[39] A. Gupta, A. Khajuria, J. Singh, S. Singh, K. A. Suri, and G. N. Qazi, "Immunological adjuvant effect of Boswellia serrata (BOS 2000) on specific antibody and cellular response to ovalbumin in mice," International Immunopharmacology, vol. 11, no. 8, pp. 968-975, 2011.

[40] A. M. Mahecha and H. Wang, "The influence of vascular endothelial growth factor-A and matrix metalloproteinase-2 and -9 in angiogenesis, metastasis, and prognosis of endometrial cancer," OncoTargets and Therapy, vol. 10, pp. 4617-4624, 2017.

[41] M. Lulli, M. Cammalleri, I. Fornaciari, G. Casini, and M. Dal Monte, "Acetyl-11-keto- $\beta$-boswellic acid reduces retinal angiogenesis in a mouse model of oxygen-induced retinopathy," Experimental Eye Research, vol. 135, pp. 67-80, 2015.

[42] P. K. Kokkiripati, L. M. Bhakshu, S. Marri et al., "Gum resin of Boswellia serrata inhibited human monocytic (THP-1) cell activation and platelet aggregation," Journal of Ethnopharmacology, vol. 137, no. 1, pp. 893-901, 2011.

[43] U. Siemoneit, L. Tausch, D. Poeckel et al., "Defined structureactivity relationships of boswellic acids determine modulation of $\mathrm{Ca}^{2+}$ mobilization and aggregation of human platelets by Boswellia serrata extracts," Planta Medica, vol. 83, no. 12/13, pp. 1020-1027, 2017. 


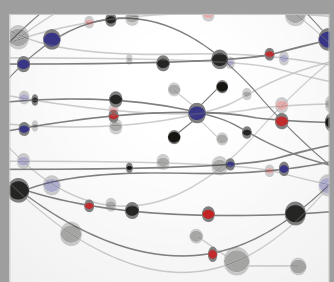

The Scientific World Journal
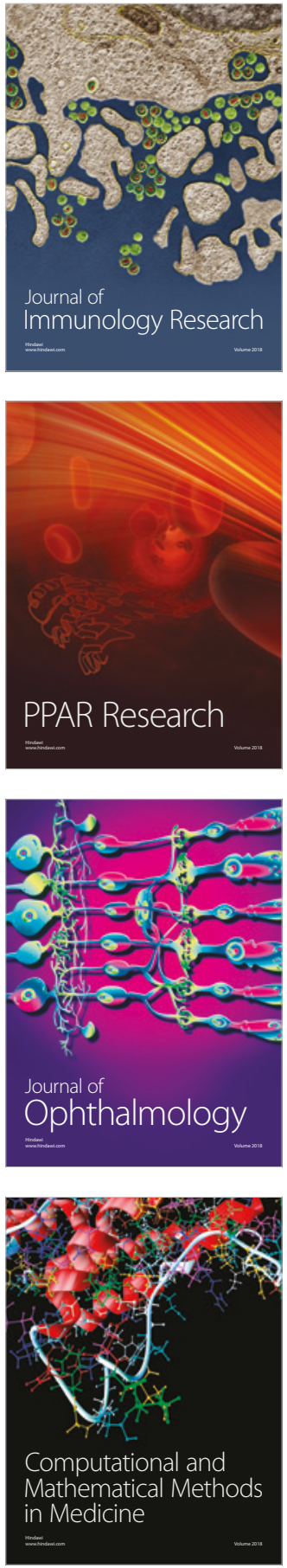

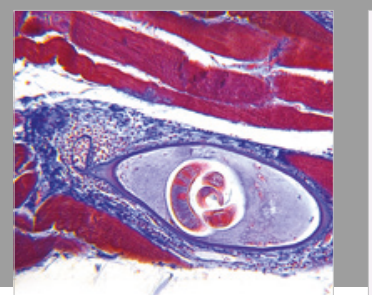

Gastroenterology Research and Practice

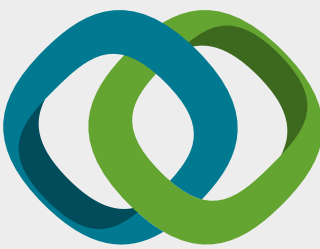

\section{Hindawi}

Submit your manuscripts at

www.hindawi.com
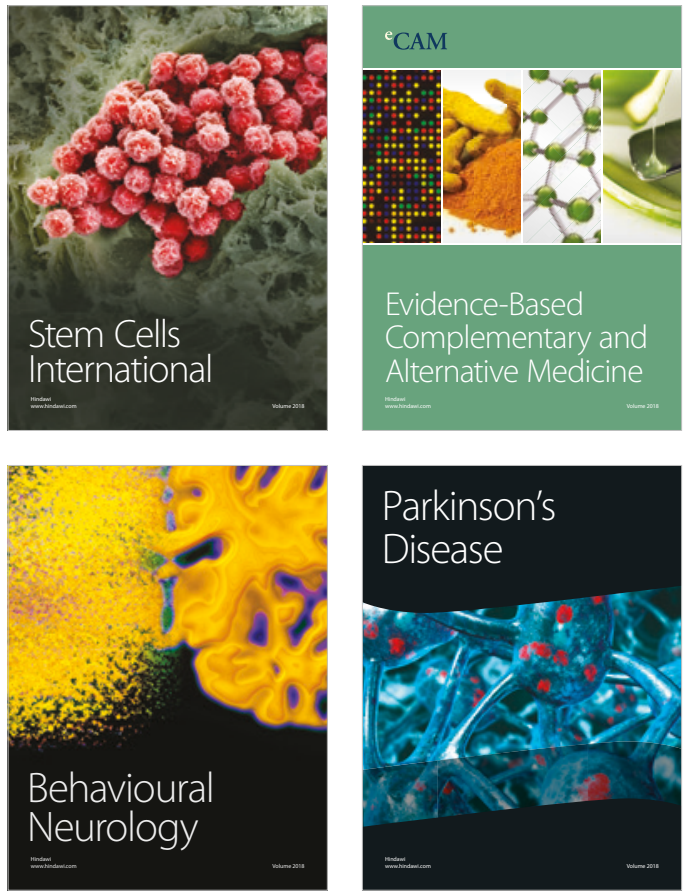

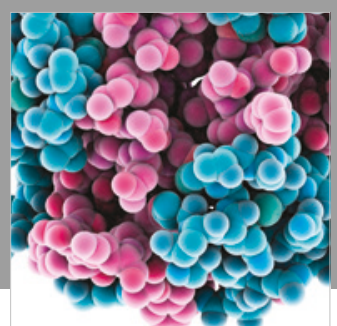

ournal of

Diabetes Research

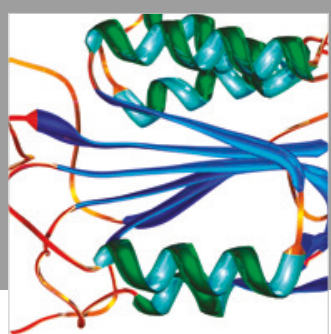

Disease Markers
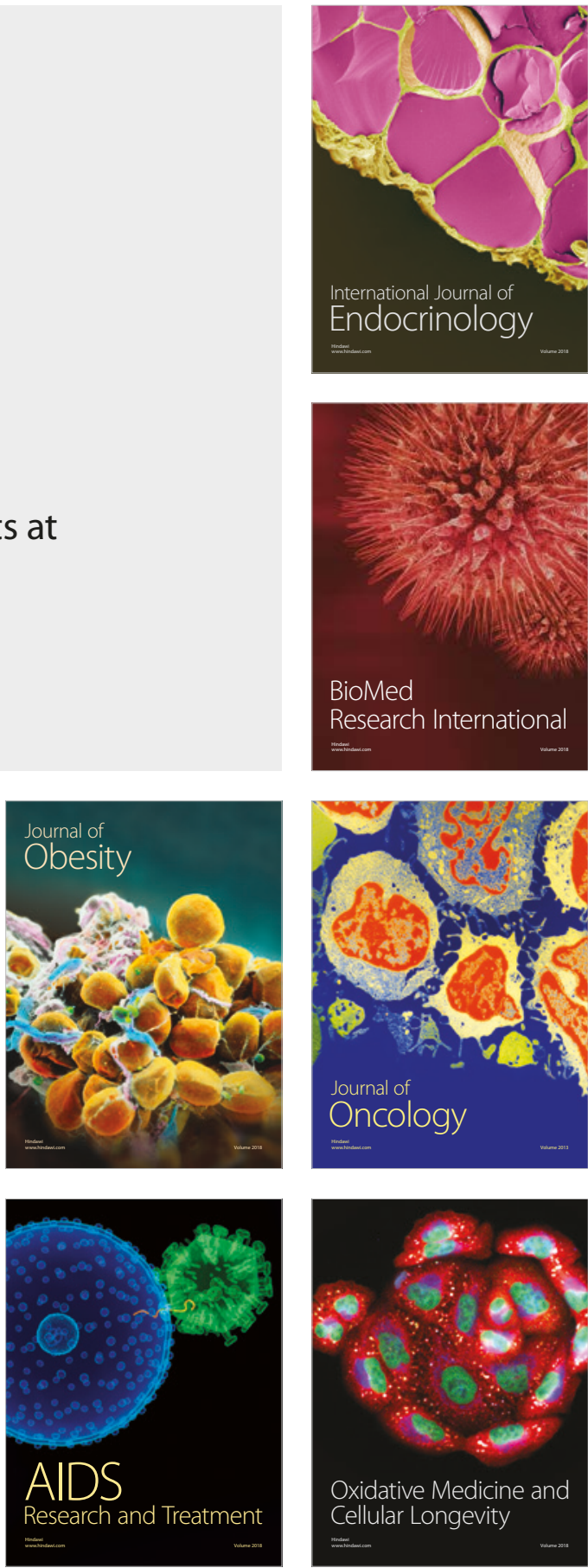